\title{
The relationship between emotional intelligence with administrators' performance at Mashhad University of Medical Sciences
}

Tooraj Sadeghi ${ }^{1}$, Mohammad Ali Kiani ${ }^{2}$, Masumeh Saeidi ${ }^{3}$, Habibolah Taghizade Moghaddam ${ }^{4}$, Mohammad Jafari Ghodsi ${ }^{4}$, Rasoul Hoseini ${ }^{5}$

${ }^{1}$ Department of Management, Islamic Azad University, Neyshabour Branch, Neyshabour, Iran

${ }^{2}$ Associate Professor, Faculty of Medicine, Mashhad University of Medical Sciences, Mashhad, Iran

${ }^{3}$ Student Research Committee, Department of Medical Education, Faculty of Medicine, Tehran University of Medical Sciences, Tehran, Iran

${ }^{4}$ Mashhad University of Medical Sciences, Mashhad, Iran

${ }^{5} \mathrm{PhD}$ Student in Business Management, Islamic Azad University, Torbat-e Heydarieh Branch, Torbat-e Heydarieh, Iran

Type of article: Original

\begin{abstract}
Background: The leadership of an organization requires specific features to adapt to changes and to survive and grow in new environments, and emotional intelligence is one of the most important attributes that can help leaders and managers respond to these changes.

Objective: This study aimed to determine the relationship between emotional intelligence with administrators' performance at Mashhad University of Medical Sciences, Mashhad, Iran.

Methods: This cross-sectional study was conducted on 100 basic and middle managers of Mashhad University of Medical Sciences, Mashhad, Iran who were selected by census method in 2016. The instrument of data collecting was the "Inventory Shrinkage", and the "Organizational performance evaluation forms". The data were analyzed by SPSS version 16 using descriptive statistics and Spearman correlation.

Results: The results showed there was a significant negative correlation between emotional intelligence and organizational performance in administrators $(\mathrm{r}=-0.214, \mathrm{p}=0.032)$. The findings also showed that among the components of emotional intelligence and administrators' performance, only components of empathy, was there a significant negative correlation $(\mathrm{r}=-0.199, \mathrm{p}=0.047)$. Also, there was no statistically significant relationship between emotional intelligence and demographic variables such as work experience, age, marital status and education level $(\mathrm{p}>0.05)$. There was no significant relationship between organizational performance and demographic variables, either ( $p>0.05$ ). But between the components of emotional intelligence, only for social skills and work place of administrators, a significant positive correlation was confirmed $(r=0.203, p=0.043)$.

Conclusions: The results of this study showed that there was a negative and significant correlation between the components of emotional intelligence and administrators' performance of Mashhad University of Medical Sciences administrators, only in the empathy component.

Keywords: Administrators, Emotional intelligence, Task performance, Iran
\end{abstract}

\section{Introduction}

Today, many organizations have undergone change, and any change requires a staff and managers who are adaptable and compatible. Moreover, social interaction in a worthy and fruitful manner is increasingly important for most managers and leaders as a key element in organizational changes in management. Studies have shown that success belongs to managers who can effectively and consistently relate to their human resources. In this regard, emotional intelligence (EI) is one of the components that can play an important role in the relationship between managers and the members of the organization and, according to Golman, is considered as a an indispensable

\section{Corresponding author:}

Associate Professor Dr. Mohammad Ali Kiani, Ghaem Hospital, Department of Pediatrics, Mashhad University of Medical Sciences, Mashhad, Iran. Tel: +98.5138412069, Fax:+98.5138411067, Email: Kianima@mums.ac.ir Received: April 12, 2017, Accepted: June 20, 2017, Published: March 2018

iThenticate screening: June 24, 2017, English editing: February 12, 2018, Quality control: February 15, 2018

(C) 2018 The Authors. This is an open access article under the terms of the Creative Commons Attribution-NonCommercialNoDerivs License, which permits use and distribution in any medium, provided the original work is properly cited, the use is non-commercial and no modifications or adaptations are made. 
condition in organization (1). Recently, some scholars have also found that emotional intelligence is more important than an IQ for a manager and leader (2). Today, emotional intelligence has been defined as a kind of intelligence, which includes both a detailed understanding of the individual's emotions and the exact interpretation of the emotional states of others. Emotional intelligence evaluates a person emotionally, which means how much the individual knows about their own emotions and feelings and how to control and manage them (3). The notable point in the field of emotional intelligence is that emotional intelligence capabilities are not inherent; they can be learned (4). In recent decades, we have witnessed scientific progress and rationalism. The basis of today's education is the logic of mental analysis, and educational programs have been set based on grammar, accountancy, analogical reasoning, instructional analysis, and the recapture of the latest information according to habit and repetition (5). Using this method, we have tried to educate high-level managers with high intelligence. But according to recent research, at best, the intelligence score contributes about 20 percent in predicting success in life, while the other 80 percent is related to other forces. Recent research indicates that there is a kind of skill in humans that is beyond the scope of the experiments of intelligence tests, and instead, this skill relates to a kind of inner, exciting and emotional talent in humans that is called emotional intelligence (6). Therefore, emotional intelligence in recent years has been a serious competitor of intelligence in analyzing successful relationships and activities that can play a better role in improving human relationships in management (7). Gellman defines emotional intelligence as a skill in which its owner can control his/her morale through self-awareness, improve it through self-management, understand its effects through empathy, and behave through management of relationships in a way that can raise one's own morale and that of others (8). Golman defines the dimensions of emotional intelligence as follows (9):

- Self-awareness: Includes features such as emotional awareness and self-confidence.

- Self-regulation: Includes self-control, reliability and innovation.

- Self-motivation: Includes enjoying progress, initiative and optimism.

- Empathy: Includes deserving traits to accompany others.

- Social skills: Includes features of effectiveness, conflict management and team capabilities.

Researchers have found a direct relationship between emotional intelligence and measurable results in business. They have found, that the morale of a manager and the associated behaviors, have profound effects on profitability. Findings of various studies have shown that there is a relationship between the score of leaders in emotional intelligence tests with their performance scores in which managers had been rated (10). Findings from research show that leaders who are more likely to have emotional abilities often have a high sense of morale. These people are skilled in group management (11). The successful management of the organization is the result of maximizing the use of leadership features such as self-awareness and self-assessment (12). Therefore, emotional intelligence leaders seem to be more committed to their organization, work better in the workplace, use emotions to improve decisionmaking and stimulate enthusiasm, trust and collaboration in other tasks $(13,14)$. Therefore, emotional intelligence can play an effective role in increasing the capabilities associated with organizational commitment of managers and staff. In this way, the success of organizations is to hire managers who can strengthen the commitment of staff, therefore, emotional intelligence can be a prerequisite for successful management, and help managers to effectively deal with emotions and feelings of others and recognize the needs of individuals and effectively challenge them. Considering the increasing tendencies and attention to human relationships in organizations, and the fact that emotional intelligence has an impact on management in organizations, and since this research has not yet been done on the managers of Mashhad University of Medical Sciences, the necessity of carrying out this research was felt.

\section{Material and Methods}

\subsection{Design and setting}

The present study is a correlational and applied study that was conducted in a cross-sectional method at Mashhad University of Medical Sciences from January 2017 to May 2017. The research population in this research was all the managers of the basic and middle levels working in the headquarters' (educational, health, research, support, student, cultural and food-medicine assistants) departments of Mashhad University of Medical Sciences, which according to the latest statistics provided by the deputy university support, are 102 people (January 2017). Since the target population and the sampling population (sample size of the research) in the current research are the same, the information was gathered in as census, by referring to the mentioned units and by presenting a letter from the research deputy of the university.

\subsection{Ethics}

This study is approved by the Research Council and the Ethics Committee of Mashhad University of Medical Sciences (Ethics code $=940440$ ) and the participation in this study was voluntary. The study objectives were described to the managers, who were asked if they wished to participate in the study. 


\subsection{Instrument and data collection}

A standard Sharing questionnaire containing 33 questions was used to measure the level of emotional intelligence. The main version of the Emotional Intelligence Questionnaire consists of 70 questions that assess several aspects of emotional intelligence (self-awareness, self-regulation, motivation, empathy, and social skills in the workplace), which after normalization in Iran, a number of test questions for various reasons, such as lacking the necessary specifications and the length of the question with non-alignment to Iranian culture, have been eliminated. As a result, the normalized test has 33 questions. This test measures 5 components of emotional intelligence. These components include self-awareness, self-control, self-motivation, social consciousness, and social skills. The emotional intelligence of managers for self-awareness component through 8 questions, self-management 7 questions, self-esteem 7 questions, social awareness 6 questions, and relationship management component are also measured using 5 questions. Each question based on a 5-point Likert scale, has been scored from 1 to 5 (minimum score is 33 and maximum score is 165). In this research, the validity of the questionnaire has been approved by 7 professors and experts from the fields of health education, medical education, social medicine, and psychiatry. Mansouri, in his master's thesis has received the internal correlation of this scale through Cronbach's alpha equal to 0.85, which shows the desirability of the test (15). Keramati and Allahiyari, in their survey, have obtained the reliability of the questionnaire equal to 0.83 (16). Each subject receives 6 separate points after answering this test, of which 5 points are related for each of the components and one point for the total score (Table 1). Standard forms of evaluation of the annual performance of the Ministry of Health were communicated from the Ministry of Health, and were used in order to measure the performance of managers. These forms evaluated managers from two dimensions: Public indicators and Specific indicators. The total score at each assessment level is 100 , with 40 points for specific indicators (minimum 0 and maximum 40 points), and 60 points for general indicators (minimum 0 and maximum 60 points). Specific indicators are the main criterion for assessing the performance of managers in their missions, programs and job descriptions, which are governed by law and regulations as the basis for evaluating their performance. Indicators of evaluation are prepared based on the operational plan and the description of the tasks of the managers. Specific Indicators forms include columns as follows: Job Description, Evaluation Indicators, Measurement Unit, Expected Quantitative Objectives, Exit Limit, Performance, Bid Score and Performance Analysis. The score of each indicator is determined by the following formula: The bid score is equal to: expected quantitative target / performance $\times$ limit of the score. General indicators are common criteria for staff performance evaluation, which provides a framework for facilitating the fulfillment of their specific functions. The general indicators of managers and staff were prepared by the deputy of management development and president human capital, and communicated to the systems. These indicators are common to all operating systems. The public indicators have been designed and communicated in the following five areas for the three groups evaluated (middle managers, basic managers, staff): Innovation and creativity: 20 points (this axis consists of 2 distinct sections, each with 10 points), training: 20 points and customer satisfaction: 20 points (18). The method of conducting the research was by gaining approval of the plan from the Deputy of Research of the university with the receipt of the letter referring to the centers, (headquarters of Mashhad University of Medical Sciences). Following approval, to obtain cooperation from research units to complete the questionnaires, we expressed the objectives of the plan and mentioned that the information of managers was extracted in general, and that including personal information was not mandatory. On the other hand, the evaluation information of the university headquarters administrators was received from the University Support Assistant Evaluation Unit in general without mentioning the participants' names.

Table 1. Scoring of Siberia Shering Test Components

\begin{tabular}{|l|l|l|}
\hline Number & Component & Questions \\
\hline 1 & Self- motivation & $1,9,15,20,21,26,31$ \\
\hline 2 & Self-awareness & $6,10,12,14,24,27,32,33$ \\
\hline 3 & Social skills & $7,8,13,19,28$ \\
\hline 4 & Self- regulation & $2,5,11,16,18,23,30$ \\
\hline 5 & Sympathy & $3,4,17,22,25,29$ \\
\hline
\end{tabular}

\subsection{Statistical analyses}

Descriptive statistics such as mean, standard deviation, frequency distribution table, percentages and charts, and inferential statistics such as Spearman correlation coefficient for expressing the relationship between emotional intelligence and organizational performance of managers as well as for expressing the relationship between emotional intelligence, organizational performance of managers with demographic variables were used to analyze the data. 


\section{Results}

Of a total of 102 managers employed at the headquarters of Mashhad University of Medical Sciences, 100 people cooperated in completing questionnaires, and 2 of them did not complete the questionnaire due to participation in different sessions and administrative missions (participation rate: $98.03 \%$ ). Of the 100 people, 32\% of the managers were in the department for support, $17 \%$ in the treatment department, $5 \%$ in the Food and Drug department, $14 \%$ in the department of education, $7 \%$ in the student-cultural department, $6 \%$ in the research department and $19 \%$ in the health ministry department. Furthermore, $86 \%$ were married and $43 \%$ had a master's degree and $37 \%$ were general physicians. Their average age was $41.76 \pm 5.724$ years and the average work experience was $16.87 \pm 6.119$ years. According to the results of Kolmogrov-Smirnov test, because the values of significance level for both emotional intelligence and performance of managers was less than the significance level $(\alpha=0.05)$, both factors have an abnormal distribution, and nonparametric tests were used to test the hypotheses. In Table 2, descriptive findings such as mean, standard deviation, minimum and maximum score of emotional intelligence and number of subjects have been presented. As you can see, among the components of emotional intelligence, self-awareness is the highest mean and social skills have allocated the lowest mean. Also, in Table 2, the mean and standard deviation of organizational performance and its components in the managers have been presented, as it is seen that the average score of managers in the specific indicators (out of 40) is higher than the general indicators (out of a total of 60). Table 3 describes descriptive statistics including mean and standard deviation of emotional intelligence variables and performance of managers by gender. As you can see, the mean of the two variables is different in both sexes. Men with a mean score of 114 in terms of emotional intelligence were in a better position than women (mean score of 111). This difference was not significant in organizational performance. To answer the question: Is the observed difference statistically significant or not? The Mann-Whitney test was used. As it is seen, men are in a better position than women in terms of emotional intelligence and organizational performance. And the difference in the scores is meaningful in both sexes $(\mathrm{p}=0.000)$. Spearman's test results showed that there is a significant and inverse relationship between emotional intelligence and organizational performance at the significant level (0.05). So, organizational performance of managers is decreased with increasing emotional intelligence $(\mathrm{r}=-0.214, \mathrm{p}=0.032)$.

Table 2. Mean and standard deviation of emotional intelligence and organizational performance and their components in Administrators of Mashhad University of Medical Sciences

\begin{tabular}{|l|l|l|l|l|l|l|}
\hline Components & Number & Mean & SD & Maximum & Minimum \\
\hline \multirow{3}{*}{$\begin{array}{l}\text { Emotional Intelligence } \\
\text { Components }\end{array}$} & Total emotional intelligence & 100 & 112 & 12.06 & 139 & 91 \\
\cline { 2 - 7 } & Self- motivation & 100 & 23 & 3.000 & 32 & 16 \\
\cline { 2 - 7 } & Sympathy & 100 & 20 & 3.094 & 27 & 13 \\
\cline { 2 - 7 } & Social skill & 100 & 17 & 3.007 & 24 & 11 \\
\cline { 2 - 7 } & Self-regulatory & 100 & 23 & 3.000 & 30 & 16 \\
\cline { 2 - 7 } & Self-awareness & 100 & 27 & 3.000 & 36 & 20 \\
\hline \multirow{3}{*}{$\begin{array}{l}\text { Organizational Performance } \\
\text { Components }\end{array}$} & Overall performance & 100 & 94 & 4.000 & 100 & 83 \\
\cline { 2 - 7 } & Proprietary indicators & 100 & 39 & 0.000 & 40 & 37 \\
\cline { 2 - 7 } & Public indicators & 100 & 54 & 4.000 & 60 & 43 \\
\hline
\end{tabular}

Table 3. Mean and standard deviation of emotional intelligence and organizational performance in Administrators of Mashhad University of Medical Sciences

\begin{tabular}{|l|l|l|l|l|}
\hline Variables & Gender & Number & Mean & SD \\
\hline \multirow{2}{*}{ Emotional Intelligence } & Male & 43 & 114 & 11.000 \\
\cline { 2 - 5 } & Female & 57 & 111 & 12.000 \\
\hline \multirow{2}{*}{ Organizational Performance } & Male & 43 & 94 & 5.000 \\
\cline { 2 - 5 } & Female & 57 & 94 & 4.000 \\
\hline Variables & Gender & Sum of squares & Mean of squares & p-value \\
\hline \multirow{2}{*}{ Emotional Intelligence } & Male & 2184 & 50 & 0.000 \\
\cline { 2 - 4 } & Female & 2165 & 50 & \multirow{2}{*}{0.000} \\
\hline \multirow{2}{*}{ Organizational Performance } & Male & 2319 & 53 & \\
\cline { 2 - 5 } & Female & 2731 & 47 & \\
\hline
\end{tabular}

In Table 4, the correlation of independent variables (emotional intelligence) with demographic variables (place of service, work experience, sex, age of managers, marriage, education and leisure time of managers) has been presented. As it is seen, there was no significant relationship between emotional intelligence and demographic 
variables at significant level (0.05). In Table 4, the correlation between organizational performance of managers with demographic variables (place of service, work experience, sex, and age of managers, marriage, education and leisure time of managers) has been presented. As it is seen, there is not a significant relationship between organizational performance and demographic variables $(p>0.05)$.

Table 4. Correlation coefficient of emotional intelligence and organizational performance of Administrators with demographic variables

\begin{tabular}{|l|l|l|l|l|l|l|l|l|}
\hline Variable & \multicolumn{2}{l|}{ Demographic variables } \\
\cline { 2 - 10 } \multicolumn{2}{c|}{} & Workplace & $\begin{array}{l}\text { Work } \\
\text { experience }\end{array}$ & Gender & Age & $\begin{array}{l}\text { Marital } \\
\text { status }\end{array}$ & Education & $\begin{array}{l}\text { Free } \\
\text { time }\end{array}$ \\
\hline $\begin{array}{l}\text { Total Emotional } \\
\text { Intelligence }\end{array}$ & $\mathrm{r}$ & 0.048 & -0.004 & -0.086 & 0.000 & -0.037 & -0.015 & 0.008 \\
\hline \multirow{nyyyyyyyyy}{*}{$\begin{array}{l}\text { Total Organizational } \\
\text { Performance }\end{array}$} & $\mathrm{p}$-value* & 0.515 & 0.955 & 0.304 & 1.000 & 0.655 & 0.848 & 0.918 \\
\cline { 2 - 10 } & $\mathrm{p}$-value* & 0.011 & 0.119 & 0.008 & 0.132 & -0.015 & -0.046 & -0.060 \\
\hline
\end{tabular}

*Spearman correlation coefficient.

\section{Discussion}

Considering that the topic of emotional intelligence is relatively new and has been taken into consideration in recent years, similar studies have not been found to suggest an assessment of emotional intelligence and the performance of managers of organizations. Moreover, most studies have been carried out on the staff of the organizations and little research and evaluation has been carried out on organizational managers. The results of this study showed that among the components of emotional intelligence, the self-awareness component has the highest average and the social skill component has the lowest average in managers of Mashhad University of Medical Sciences. According to Golman, the component of (Self-awareness of your emotions) is the main axis of emotional intelligence (8). One of the most important features of people with this ability is the greater skill in controlling and directing the events of life. The ability to control and regulate their emotions and their feelings, according to research of Siiruchi et al., has a reverse relationship with depression, despair, and disappointment, and these people respond with more optimism and more hopeful thoughts to stressful and unpleasant events (18). On this result, it can be analyzed in such a way that staff can improve the performance of themselves and their colleagues if they can raise their self-awareness and obtain a proper understanding of the reality of their existence and gain access to their deeper capacities. Methods such as effective listening, stress management and time management, and effective collaboration with people with different cultures and backgrounds are self-awareness indicators. Self-awareness helps people to become aware of their strengths and weaknesses. This form of self-awareness contributes to the effectiveness of management in various ways (8). The next component is social skill means control of emotions in appropriate ways that comes after self-awareness. This component is vital for the establishment and maintenance of effective relationships with others, and is closely related to the intrinsic aspects of leadership and interpersonal relationships. Some studies have shown that people with social skills know exactly what speech and actions affect others. An example of social skills is empathy. Empathy means the ability to enter others' feelings or the ability to understand the feelings of staff in the process of intelligent decision making by an individual or group (19). Considering the low average score of social skill in the middle and basic managers of Mashhad University of Medical Sciences, it can be concluded that these managers are weak in understanding the feelings of their subordinate staff and in establishing proper communication with them. In turn, they can be effective in reducing productivity. Self-regulatory is another component of emotional intelligence. Effective people in this area can avoid negative emotions such as hopelessness or anxiety and irritability. These people encounter fewer problems in life, and if a problem arises, they can return from a troublesome and uncomfortable situation to desirable conditions quickly. This component was moderately high in managers of Mashhad University of Medical Sciences. The results of this study also showed that the average score of organizational performance of managers in specific indicators (manager's description of tasks) is more than general indicators (initiative and creativity, education and customer satisfaction). Perhaps it can be deduced that due to lack of social skills in managers, they prefer only to do their job assignments in a valuable way without proper communication with their colleagues, the masters and their subordinate staff, and in this way, to attract the personal satisfaction and support of upstream managers. The results of various researches show that self-awareness and selfregulation skills are related to the individual domain, but social skills and empathy go back to how people interact with the community and more about the ability of individuals to maintain their relationships with others in a correct way (19). Emotional intelligence is a skill in which its holder can control their own spirit by self-awareness, can improve it by self-regulation, can understand its effects by empathy (social skill) and can manage relationships in a way which enhances the spirit of oneself and others (19). Totally, based on the results of the analysis of the data of 
this research, it can be seen that there is a positive and significant correlation between the components of emotional intelligence (social skill component) and the place of service of managers. It can be deduced that when the work environment of the managers is in accordance with their taste and spirit, and there is no problem in this regard, the level of social skills is also promoted and managers use the appropriate managerial methods (20). Social skills training is also one of the ways to increase emotional intelligence. These trainings include programs for controlling anger and wrath, empathy, recognizing similarities and differences of people, expressing politeness and intimacy, and complicity, self-governance, communication, risk assessment, positive self-affirmation, problem-solving, and decision-making in creating goals and resistance to pressure. Therefore, these skills can be taught alongside emotional intelligence training $(18,5)$. The results of various studies have shown that emotional intelligence can be used to create an enabling environment for effective communication between staff so that staff and managers can freely apply their expectations to get maximum performance and organizational productivity, and take steps in order to advance the organization's programs (21-24). On the other hand, demographic components such as their place of work and their gender can also be considered as variables that have a positive or negative effect on managers' performance when selecting managers for the organizational post. According to the research findings, it is recommended to giving knowledge and empowerment of managers in relation to emotional intelligence and its components. Considering that the spatial range of this research is Mashhad University of Medical Sciences; it is recommended that this research be done in other medical sciences universities and the results be compared with each other. Since the research method was descriptive-analytic, it is recommended that other research methods such as qualitative studies be also used and its results be compared with the present study. In this research, the information collected through the questionnaires has been considered as the correct answer and there is no information about its accuracy. Obtaining information at different times from the research units that affect the quality of their responses is of other limitations of the research. The psychological and spiritual status of the research units has influenced their responses when answering the questions of the questionnaire, which has been beyond the control of the researchers. Evaluating the level of emotional intelligence and its components in this research is limited to the research tool's score and it is considered as a kind of limitation.

\section{Conclusions}

In summary, the findings of this study showed that there is a significant negative correlation between emotional intelligence and organizational performance of managers. Since the components of emotional intelligence are acquired; it is possible to increase their communication skills by training these skills to the managers and, increasing the efficiency and performance of managers at the organization level by tailoring their job conditions. The statistical population of this research was merely the basic and middle managers of Mashhad University of Medical Sciences. Therefore, it is recommended that other managers and staff of the university be compared in future research.

\section{Acknowledgments:}

This study is extracted from the thesis by Dr. Mohammad Ali Kiani (M.S thesis), Islamic Azad of University Neyshabour Branch, Iran. We thank and appreciate all the managers of Mashhad University of Medical Sciences who participated in this study. This project is approved by the Research Council of Mashhad University of Medical Sciences and we thanks from the university's vice chancellor for funding the project.

\section{Conflict of Interest:}

There is no conflict of interest to be declared.

\section{Authors' contributions:}

All authors contributed to this project and article equally. All authors read and approved the final manuscript.

\section{References:}

1) Goleman D, Boyatzis R, Mc Kee A. Emotional Intelligence in Organizational Management and Leadership. Tehran: Industrial Management Organization Publications; 2006.

2) Curtis H, O'Donnell C, Phillain E. Principles of Management. Tehran: Sharif University of Technology, Scientific Publishing Institute; 2001.

3) Goleman D. Emotional intelligence the ability to love and love. Tehran: Roshd; 2003.

4) Mokhtaripour M, Siadat SA, Amiri Sh. The Relationship between Theory of Emotional Intelligence and Leadership Theories. Executive Management Research. 2006; 6(21): 39-57.

5) Rezaeian A, Keshtgar A. The Relationship between Emotional Intelligence and Organizational Commitment. Message from management. 2007; 27: 27-39. 
6) Austin J. Personality Well-Being and health correlates of trait Emotional Intelligence. Personality and individual differences. 2005; 38(3): 547-58. doi: 10.1016/j.paid.2004.05.009.

7) Armstrong M. Strategic Human Resource Management. Tehran: Publications Office of Cultural Research; 2003.

8) Goleman D. Emotional Intelligence why it can matter more than IQ. London: Bloomsbury Publishing PLC; 1995.

9) Stys Y, Shelley B. A review of the emotional intelligence literature and implication for correction, research branch correction serrice of Canada. 2004: 150.

10) Hasanzadeh R. Investigating the Emotional Intelligence of Managers and its Relationship with their Demographic Characteristics. Educational research. 2007; 4(15): 25-37.

11) Mokhtaripour M, Siadat SA. Management and leadership with emotional intelligence. Tadbir. 2005; 15: $85-8$.

12) Aghayar S, Sharifi P. Emotional Intelligence and Management. Management. 2007; 18: 89-92.

13) Ansari Renani Gh, Arastoo I. Emotional Intelligence and Transforming Managers in Iranian Insurance Companies. Insurance industry. 2008; 23(1,2): 91-123.

14) Eivazi Z, Bagherzadeh D. Emotional Intelligence: A Tool for Managers. Bimonthly of Human development of the police. 2008; 5: 90-103.

15) Mansouri M. Comparative Study of Emotional Intelligence and Social Adjustment of Students. BA Thesis. Sistan and Baluchestan University, Zahedan. 2008.

16) Keramati MR, Allahyari R, Shahbazi B. The Relationship between Emotional Intelligence and Job Satisfaction among Employees of Government Departments in Ghoochan City. Journal of Leadership and Educational Management of Islamic Azad University of Garmsar Branch. 2011; 6(4): 117-36.

17) Forms for managers and staff. Available from: http://mdar.behdasht.gov.ir/

18) Ciaruchi J. Emotional intelligence in everyday life. 2007: 21-53.

19) Golman D. What makes a leader? Journal of Harvard Business Review. 1998; 76(6): 93-102.

20) Musavi M. Emotional intelligence and its effect on increasing the capabilities of employees and managers in life and work. Tehran: Automobile industry; 2007.

21) Mokhtaripour M, Siadat SA, Amiri Sh. The Relationship between Theory of Emotional Intelligence and Leadership Theories. Executive Management Research. 2006; 21(6): 39-57.

22) Zahed Babolan R. The role of emotional intelligence and leadership styles in prediction. Leadership Effectiveness of University Directors. Educational Sciences. 2010; 3(9): 14-89.

23) Casey D. Cobb and John D. Mayer. Emotional Intelligence: what the Research says. Educational Leadership. 2000; 58: 14-18.

24) Rosete D, Ciarrochi J. Emotional intelligence and its relationship to workplace performance outcomes of leadership effectiveness. Journal of leadership \& organization development. 2005; 26(5): 388-99. doi: 10.1108/01437730510607871. 